\title{
MIXED-MODE LOADING CONDITIONS IN IMPACTED IZOD-TYPE SPECIMENS
}

\author{
R. PODLESCHNY and J.F. KALTHOFF \\ Ruhr-Universität Bochum, Experimentelle Mechanik, Postfach \\ 102148, D-4630 Bochum, Germany
}

\begin{abstract}
Résumé: Les conditions de chargement à la pointe d'une entaille ou d'une fissure dans les éprouvettes d'impact IZOD ont été étudiées au moyen d'une méthode de caustique par ombre optique. Dans les tout premiers instants un champ de contrainte asymétrique a été observé, résultant des conditions de chargement en mode mixte mode-I/mode-II à la pointe de l'entaille. Ce n'est que plus tard que prédominent les conditions non perturbées en traction. Les limites temporelles sont établies à partir desquelles lesinfluences du mode II peuvent être ignorées. Par ailleurs, l'influence des effets de chargement en mode II surperposé, au début de l'impact, est quantifiée.

Abstract - The loading conditions at the tip of a notch or a crack in impacted Izod specimens are investigated by means of the shadow optical method of caustics. For the early time range an asymmetric stress field is observed, resulting in a mixed mode-I/mode-II loading condition at the notch tip, oniy later on, practically undisturbed tensile conditions of loading prevail. Time limits are established from which on mode-II influences can be ignored, furthermore, the influence of the superimposed mode-II loading effects at the beginning of the impact event are quantified.
\end{abstract}

\section{Introduction}

The Izod impact test is one of the standard methods of test for notched bar impact testing of metallic materials. Nowadays this test is also applied to other new materials as ceramics or plastics. In principal the Izod test configuration represents a notched cantilever beam that is impacted by a striking hammer/1/ (Fig. 1). Due to the resulting bending of the beam, tensile stresses are assumed to butid up at the notch tip; with proceeding time these stresses increase until the specimen finally fails under a mode-I condition of loading. This argumentation is based on a quasi-static consideration of the impact event. Actually, however, impact loading of the specimen represents a dynamic process. Thus, it is essential to look at the fully dynamic behaviour of the specimen including wave propagation and vibrational processes. These processes can indeed be very large, and are demonstrated by experiments undertaken by Kalthoff et a1. $/ 2 /$. In these experiments a specimen is loaded by an impacting mass at its precracked side, similar as in the Izod test, but the load is applied very near to the crack (Fig. 1). Totally different stress conditions to those expected for an Izod specimen are observed: for high impact velocities the specimens fail at small times to fracture under mode-II dominated stress conditions.

This paper analyzes the influences of dynamic effects on the stress condition at a crack tip in an Izod-type specimen and quantifies the mixed mode stress conditions that are expected to exist for certain periods of time. Further investigations on the general behaviour of these effects for more generalized loading arrangements are presented in $/ 3 /$.

\section{Experimental Realization}

The stress conditions at the tip of a crack in a specimen of Izod-type were investigated by means of the shadow optical method of caustics. With this technique any 


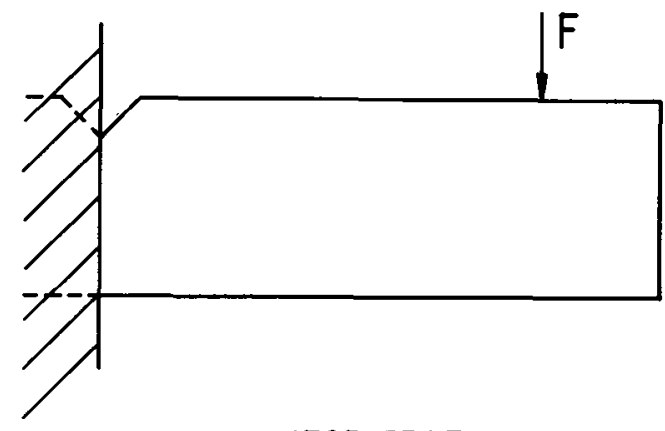

IZOD TEST

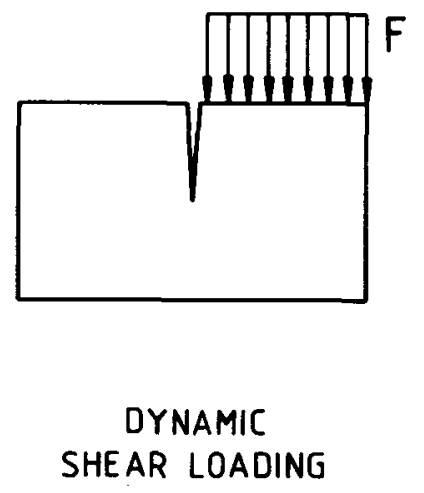

Fig. 1 Loading arrangements for impact experiments

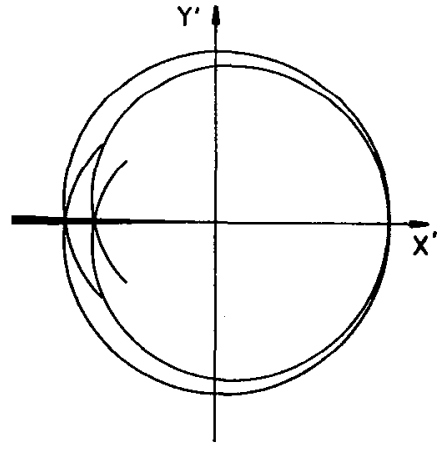

MODE-I

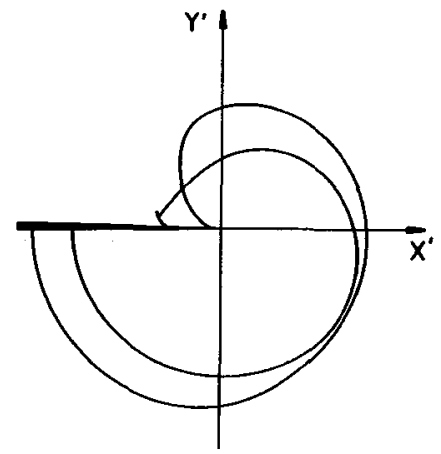

MODE-II

Fig. 2 Theoretical caustics for the optically anisotropic material Araldite B

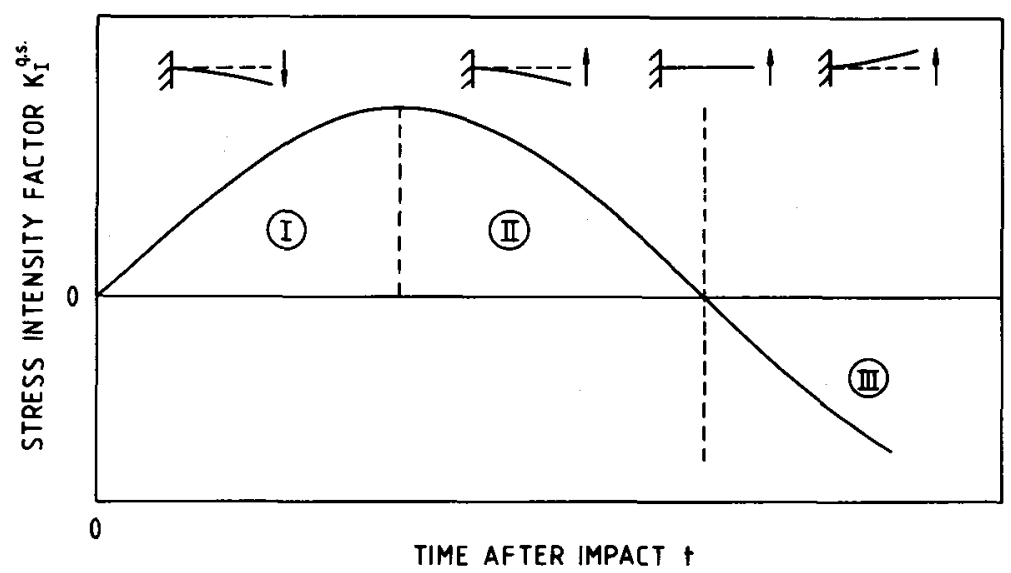

Fig. 3 Loading behaviour of an impacted Izod-type specimen, quasi-static approximation (schematically) 
kind of stress concentration problems can be analyzed in both transparent or opaque materials /4/. In these investigations specimens made from the epoxy resin Araidite $B$ were utilized, a transparent model material which combines good elastic with good optical properties. Since Araldite B is an optically anisotropic material a double caustic with a complex geometry results. A general solution for this problem was derived by the authors /5/ for mixed-mode conditions of loading, that allows for the determination of the stress intensity factors $\mathrm{KI}$ and $\mathrm{KII}$. The caustic for a purely mode-I loaded crack shows a symmetrical shape (Fig. 2); for mode-II loading the shape becomes asymmetrical. With mixed-mode conditions of loading the loss of symmetry increases with increasing amount of superimposed mode-II loading.

The specimens were clamped at one end. The geometry of the specimens were chosen similar to the one of Izod specimens, but the absolute measurements were enlarged in order to allow for an undisturbed application of the shadow optical method of caustics (see Fig. 4). The absolute measurements of the specimen were: distance between the crack and the end of the specimen $S=280 \mathrm{~mm}$, specimen heigth $W=100 \mathrm{~mm}$, distance between the crack and the impact point $1=220 \mathrm{~mm}$, and thickness $B=10 \mathrm{~mm}$. The distance between the loading fixture and the crack was chosen $15 \mathrm{~mm}$ in order to visualize the crack tip. Instead of a notch or a fatigue crack, saw cuts were used in order to use a fracture mechanics description and to also allow for compressive stress concentrations to build up. The depth of the saw cuts were $20 \mathrm{~mm}$ and $50 \mathrm{~mm}$. The depth of 20 $\mathrm{mm}$, i.e. $\mathrm{a} / \mathrm{w}=0.2$, represents the actual Izod-test configuration. The depth of $50 \mathrm{~mm}$, i.e. $a / W=0.5$, simulates the conditions usually used in fracture mechanics with precracked specimens. The specimens were loaded in a drop weight tower at impact velocities up to $5 \mathrm{~m} / \mathrm{s}$, corresponding to a maximum avallable energy of $70 \mathrm{~J}$. The experiments were performed with velocities in the range of $0.3 \mathrm{~m} / \mathrm{s}$ to $5 \mathrm{~m} / \mathrm{s}$. A CranzSchardin 24 spark high speed camera was used to register dynamic caustics durting the impact event. Time intervals between $0.4 \mu \mathrm{s}$ and $4 \mathrm{~ms}$ from picture to picture can be chosen.

\section{Experimental Results}

\subsection{Specimen Response in General}

A quasi-static consideration of the loading situation in an Izod specimen results in a sinusoidal curve for the stress intensity factor $K I$ as a function of time $t$ (Fig. 3). During the beginning of the impact process, time range $I$, the specimen bends downwards and an increasing $K_{I}$ can be observed. The point of maximum $K_{I}$ is also the point of maximum bending. At this time the hammer has transfered all of its energy to the specimen. For subsequent times,. range II, the specimen moves upwards, thereby accelerating the hammer in a direction opposite to the original impact direction. $\mathrm{KI}$ decreases until the starting position is reached, i.e. the notch tip is stress free. With increasing time; range III, the movement continues in the upward direction and negative $\mathrm{KI}_{\mathrm{I}}$-values result. For fracture tests usually only the time range $\mathrm{I}$ is of importance.

Since an impact experiment represents a displacement controled test, the stress intensity factors scale with the impact velocity $v_{0}$ of the falling hammer, thus it is possible to normalize the results by $1 / v_{0}$ to obtain unique $k(t)$-curves when different impact velocities are chosen. Furthermore, since bending of the specimen is controled by the stiffness of the specimen, it is appropriate to further normalize the $K(t)-$ curves by stiffness parameters / $6 /$ : The $K$-scale is normalized by the quantity $\sqrt{ } W / \sqrt{E}$, where $E=$ Young's modulus and $W=$ height of the specimen, the time-scale is normalized by $\sqrt{ } E$. A more detailed consideration of the impact event shows that the actual $K(t)-$ curves are additionally influenced by dynamic effects in form of superimposed vibrations, the curve shown by Fig. 3 only represents the quasi-static part of the loading condition.

\subsection{Long Time Response}

Experiments with low impact velocities in the range of $0.3 \mathrm{~m} / \mathrm{s}$ to $0.5 \mathrm{~m} / \mathrm{s}$ were performed not leading to fracture. With these experiments the time ranges I and II have been investigated in order to get an overview on the long time response of the speci- 


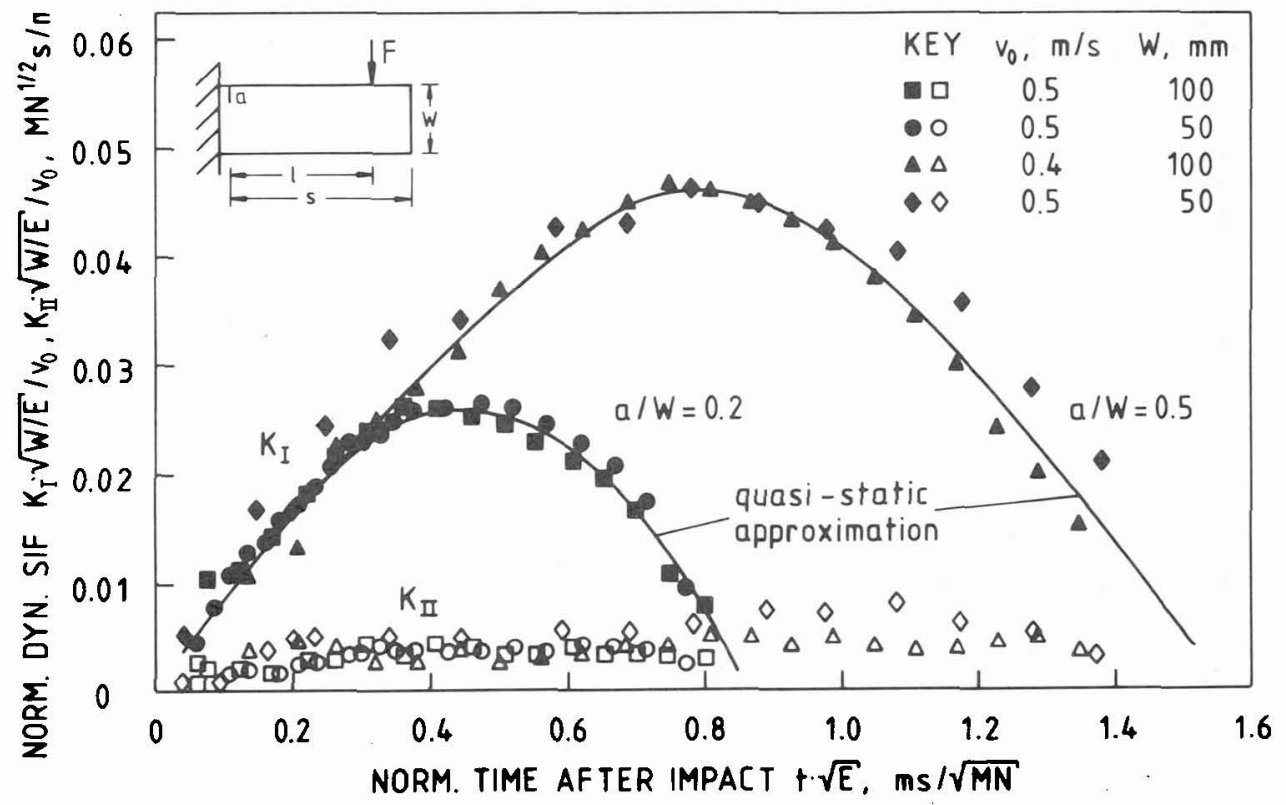

Fig. 4 Long time stress intensity history

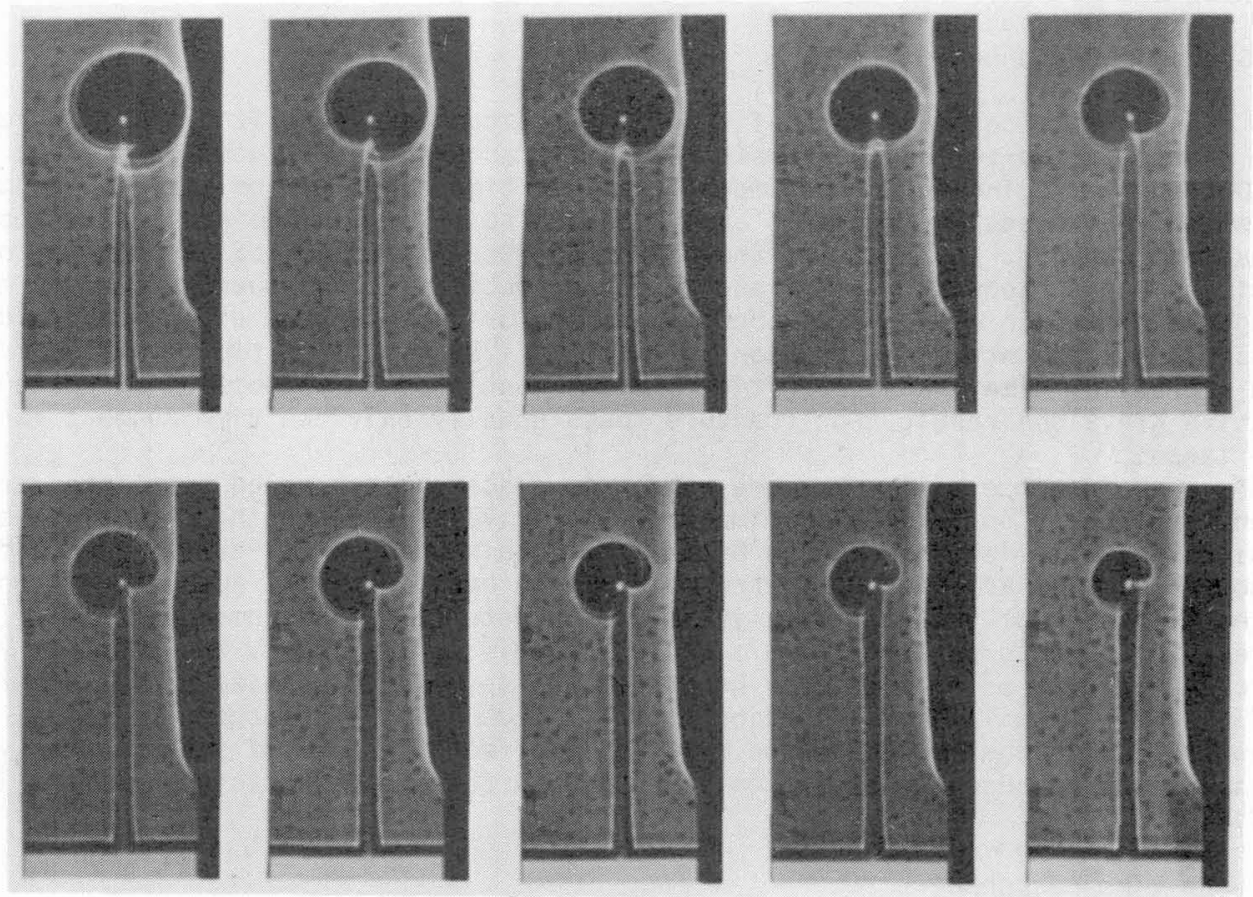

Fig. 5 High speed series of shadow photographs $(a / w=0.5$, time interval: $32 \mu s)$ 
longer time. This is plausible with regard to the above stiffness consideration since the specimen becomes more compliant. Furthermore, the larger crack length also results in an increase of the stress concentration at the crack tip. For the early time range, the K-curves are identical for different crack lengths, but the shorter the crack, the earlier the $K$-curve leaves the nearly linear regime and reaches its maximum. The experiments also show, that a pure mode-I situation at the crack tip does not exist, some shear loading is superimposed. But $\mathrm{KII}$ is small in comparison to $\mathrm{KI}$ and very likely will not affect the crack inttiation process seriously, so that mode-II influences can be neglected for practical applications. It is concluded, therefore, that the Izod test will yield mode-I loading conditions in the case of long times to fracture.

\subsection{Short Time Response}

The investigation of long times after impact does not give information on the stress conditions for early time ranges. During the beginning of the impact process wave propagation effects become more important than the bending effect discussed above. Therefore, experiments were performed with impact velocities in the range of $1 \mathrm{~m} / \mathrm{s}$ to $5 \mathrm{~m} / \mathrm{s}$, i.e. velocities which necessarily lead to fracture, in order to specifically investigate these wave effects.

Figure 5 shows a series of shadow photographs which are taken at early times in an experiment with a specimen of $100 \mathrm{~mm}$ height impacted at $5 \mathrm{~m} / \mathrm{s}$. The strongly asymmetrical shape of the obtained caustics shows a high influence of $\mathrm{K}_{\mathrm{II}}$ on the loading condition. It can also be seen that the longer branch of the caustic is at the right side of the crack at early times but afterwards at the left side. This indicates a change in sign of $\mathrm{KII}_{\mathrm{I}}$. A $\mathrm{KI}_{\mathrm{I}}$-dominated loading situation can be deduced from the more symmetrical shape of the caustic for later times.

Figure $6 \mathrm{a}$ shows quantitative data of the time dependance of $k$ for a crack length of $a / w=0.2$. Because of the increased influence of wave propagation effects a purely quasi-static consideration is not appropriate anymore. For these experiments it is speculated that the longitudinal wave velocity $\mathrm{Cl}_{L}$ for a state of plane stress (because of the small specimen thickness in comparison to the other measurements) controls the experiments. Thus it is appropriate to normalize the time scale in these cases by the time a longitudinal wave needs to travel the distance between the point of impact and the crack, $1 / \mathrm{cl}$. The time, for which loading at the crack tip starts, is defined as zero. The results show that $K_{I}$ increases steadily. Also shear loading at the crack tip is observed but in contrast to the results obtained for large times, $K_{I I}$ is much larger, it amounts up to about $50 \%$ of the $\mathrm{KI}_{\mathrm{I}}-\mathrm{value}$. The time behaviour of the $\mathrm{KII}_{\mathrm{I}}$ curve is remarkable: $K_{I I}$ is negative at the beginning, at later times $K_{I I}$ changes sign. This behaviour could already be seen from the shadow graphs shown in Fig. 5 . It is concluded, therefore, that the Izod-test does not represent a pure mode-I test for early time ranges.

It is appropriate to discuss the results presented above by considering a special ratio of the stress intensity factors $K_{I}$ and $K_{I I}, i . e . \operatorname{sgn}\left(K_{I} * K_{I I}\right) *\left|K_{I I}\right| /\left(\left|K_{I}\right|+\left|K_{I I}\right|\right)$. Figure $7 \mathrm{a}$ shows the obtained results in the format of the above defined quantity. The value 0 represents a pure mode-I loading and the values \pm 1 represent pure mode-II loading. Figure $7 \mathrm{a}$ in addition to the results for large specimens also includes results obtained for small specimens. At the beginning of the loading process a significant mode-II contribution can be recognized. At the time of about $1 \mathrm{l} / \mathrm{CL}$ and the time of about $3 \mathrm{l} / \mathrm{CL}$ maxima of mode-II exist. Only after a time larger than $5 \mathrm{l} / \mathrm{CL}_{2}$ a nearly mode-I situation at the crack tip is observed, indicating that the early time range is influenced by wave propagation effects. Again, the good agreement of the experimental data obtained for smal1 and for large specimens shows the validity of the chosen normalization of the time scale.

Figure $6 b$ shows $k$-curves for $a / w=0.5$. For the longer crack length the loading behaviour described above becomes even more pronounced. The absolute values of $K_{I I}$ become larger, both for the time range where $\mathrm{KII}_{\mathrm{I}}$ is negative and where it is positive. With increasing time $K_{I}$ becomes dominant. For a better interpretation of the results it is useful again to look at a plot of the specific K-ratios define above (Fig. $7 \mathrm{~b}$ ). The general trend of the curves is identical for both crack lengths, $a / W=0.2$ and $a / W=0.5$, but the maxima are much larger for the longer crack. Thus longer cracks are much stronger influenced by mode-II effects than shorter ones. Even a pure mode-II 
a)

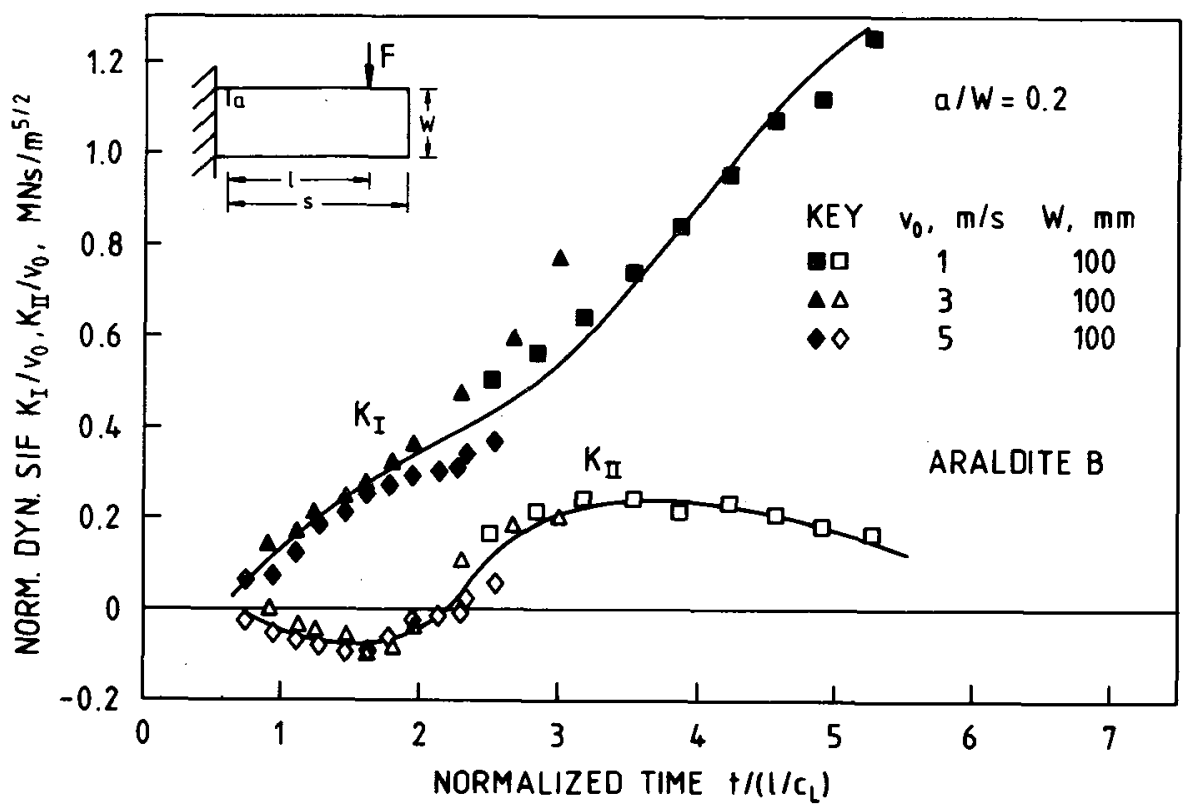

b)

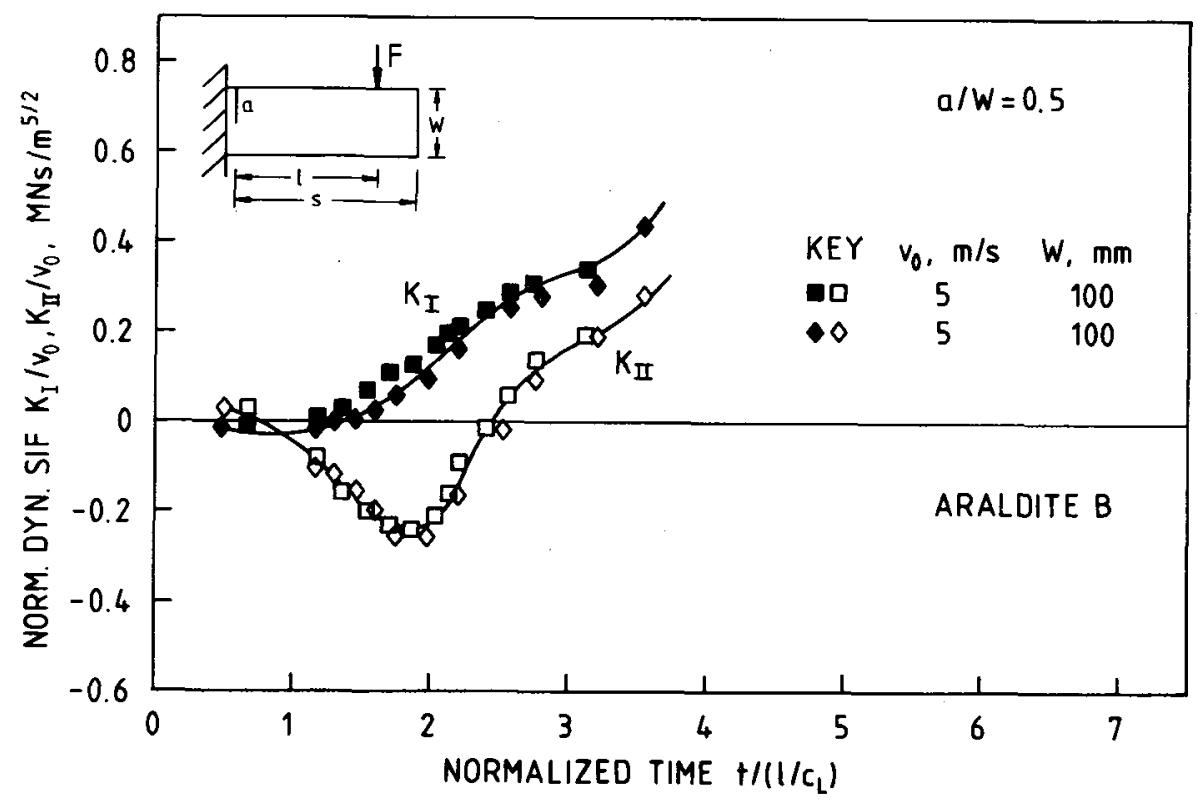

Fig. 6 Short time stress intensity history, a) $a / w=0.2$ b) $a / w=0.5$ 

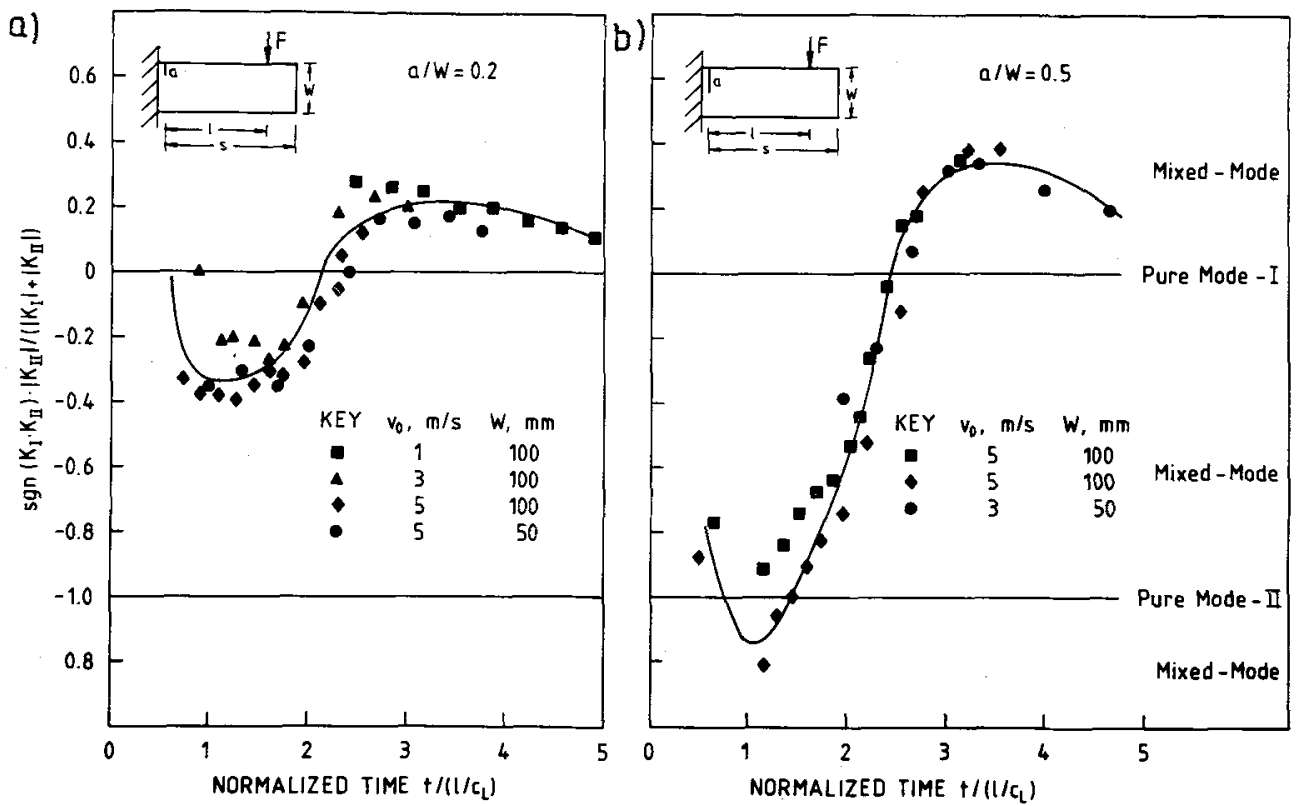

Fig. 7 Short time stress intensity history, normalized, a) $a / w=0.2$ b) $a / w=0.5$

loading is also observed for a short period. The times at which the maxima are observed are identical with those for short cracks: at about $11 / \mathrm{CL}$ and about $31 / \mathrm{CL}$. The second maximum is smaller than the first one. Obviously the dynamic effects can be represented by an oscillation with damped amplitude. After a time larger than 5 1/CL the mode-II influence can be neglected and will not disturb the crack initiation process any longer.

\section{Summary and Conclusions}

Experimental investigations have been performed in order to analyze the loading condition at the tip of a notch or a crack in an impacted Izod-type specimen, especlally with respect to wave propagation effects and their influence on the loading situation. For large time ranges of the impact event the data show small amounts of shear contributing to the stress condition at the crack tip. Their infiuence on the crack initiation process most likely can be neglected. For early time ranges, however, dynamic effects control the stress condition resulting in a strong mode-II contribution. The longer the crack, the larger the amount of shear loading. The time dependance of this superimposed shear loading is remarkable: $K_{I I}$ is negative at the beginning of the loading process but later on $\mathrm{K}_{\mathrm{II}}$ changes sign. This behaviour would cause a change of the crack path direction: applying the maximum tangential stress criterion the crack would propagate towards the impact point if initiated at early times, an effect that would not be expected from static considerations. These dynamic influences are controled by the longitudinal wave velocity. After a time of $51 / \mathrm{cL}$ a nearly mode-I condition of loading prevails, thus, only after this time the Izod-test can be used as a mode-I test - serving its original function. The normalized time $1 / \mathrm{CL}$ used for discussion of the data is independent of the specimen size, however, since it depends on the longitudinal wave velocity, it is affected by material proporties. Thus it is possible to transfer the experimental results to specimens of real Izod size and to other materials. 
There is no danger of mode-II dominated crack initiation for materials with high $\mathrm{KIC}^{-}$and $\mathrm{CL}^{-v a l u e s}$ as e.g. for steels, but also for ceramics, in particular because of the large values of the wave propagation velocities for this material. On the other hand, specimens made from materials characterized by a low longitudinal wave velocity and a low KIc-value may break at a mode-II influenced stress condition if the fracture time is sufficientiy low. Polymeric materials may fulfill these conditions. These materials, like Araldite $B$, can easily break during the mode-II influenced time range. Therefore, precautions must be taken in performing an Izod-test with polymers to get a valid KIc-value. Such specimens may break under a stress condition which is strongly influenced by mode-II components, so that the obtained critical stress intensity factor will be invalid. A specimen must have a fracture time larger than $5 \mathrm{l} / \mathrm{cL}$ to conduct a valid Izod test.

\section{References}

/1/ ASTM, Section 3, E 23-88, 1990, 197-212.

12/ Kalthoff, J.F., Winkler, S., Failure Mode Transition at High Rates of Shear Loading, Proc. Int. Conf.: "Impact '87", May 18-22, Deutsche Gesellschaft für Metallkunde eV, Bremen, 1987, 185-195.

13/ Podleschny, R., Kalthoff, J.F., A Novel Arrangement for Mixed-Mode Impact Testing - Characterization by Shadow Optics, Proc. Int. Conf.: "Mixed-Mode Fracture and Fatigue", July 15-17, Vienna, 1991.

14/ Kalthoff, J.F., Shadow Optical Method of Caustics, Chapter 9, Handbook on Experimenta1 Mechanics, (A.S. Kobayashi Ed.), Prentice-Ha11, 1987, 430-500.

/5/ Podleschny, R., Kalthoff, J.F., Verbesserte Best immung bruchmechanischer Schub-(ModusII)-Spannungs intensitätsfaktoren mit $\mathrm{Hilfe}$ des schattenoptischen Kaust ikenverfahrens, Tagungsband: "13. GESA-Symposium Experimentelle Mechanik", May 10./11., Bremen, VDI Berichte 815, 1990, 323-335.

16/ Böhme, W., Experimentelle Untersuchungen dynamischer Effekte beim Kerbschlagbiegeversuch, Dissertation, Fachbereich Mechanik der TH Darmstadt, 1985. 